\title{
Health-related quality of life associated with erythema nodosum leprosum in Purulia, West Bengal, India
}

JOYDEEPA DARLONG ${ }^{\mathrm{a}}$ PITCHAIMANI GOVINDHARAJ ${ }^{\mathrm{b}, \mathrm{c}}$, BHABANANDA MAHATO ${ }^{d}$, DIANAN. LOCKWOOD ${ }^{\mathrm{e}} \&$ STEPHEN L. WALKER ${ }^{\mathrm{e}}$

${ }^{\mathrm{a}}$ Head - Knowledge and Management, The Leprosy Mission Trust India, New Delhi, India

${ }^{\mathrm{b}}$ Physiotherapist (at time of study), The Leprosy Mission Hospital, Purulia, West Bengal, India

${ }^{\mathrm{c}}$ Lecturer, Department of Allied Health Sciences, Sri Ramachandra Institute of Higher Education and Research (DU), Chennai, Tamil Nadu, India ${ }^{\mathrm{d}}$ Physiotherapy Department, The Leprosy Mission Hospital, Purulia, West Bengal, India

${ }^{\mathrm{e}}$ Faculty of Infectious and Tropical Diseases, London School of Hygiene and Tropical Medicine, London, UK

Accepted for publication 2 January 2020

\begin{abstract}
Summary
Objectives: To determine the impact of erythema nodosum leprosum (ENL) on healthrelated quality of life (HRQoL) of persons affected by leprosy compared to individuals without ENL using the Medical Outcomes Study: 36-Item Short Form Survey (SF-36). Methods: Individuals with a diagnosis of leprosy completed the Bengali version of the SF-36. The responses to the items of the surveys were coded, summed and transformed into a score for each of the eight domains. A lower score reflects a worse HRQoL.

Results: 290 individuals with a median age of 32 years (Range 14-82) participated. Individuals with ENL and those with isolated neuritis had significantly lower mean scores in all domains compared with individuals without reaction or neuritis except the domain of physical functioning in those with ENL.

Conclusions: This study demonstrates an association of reduced HRQoL with ENL compared to individuals without reaction or neuritis.
\end{abstract}

Keywords: Erythema nodosum leprosum, health related quality of life, leprosy, nerve function impairment, Purulia

Correspondence to: Joydeepa Darlong, Head - Knowledge and Management, The Leprosy Mission Trust India, New Delhi, India (e-mail: joydeepa.darlong@leprosymission.in) 


\section{Introduction}

Leprosy is a disabling disease that may lead to stigma and discrimination. The World Health Organization (WHO) multi-drug therapy (MDT) has been successful in treating the infection. However individuals still experience disability secondary to nerve function impairment. Over 200,000 new cases of leprosy were reported to WHO in 2017 and $63 \%$ of these cases were from India. ${ }^{2}$ In India $4.6 \%$ of individuals had Grade 2 disability at the time of diagnosis. ${ }^{3}$ Leprosy patients continue to develop disability during or after MDT. ${ }^{4}$ Disability is associated with worse health related quality of life (HRQoL). ${ }^{5}$

HRQoL is defined as a person's perception of his or her physical and mental health and covers broad domains including physical, psychological, economic, spiritual and social wellbeing. ${ }^{6} \mathrm{HRQoL}$ in leprosy is hampered in the areas of prejudice, marginalization, stigma and illness. ${ }^{7,8}$ Leprosy has been shown to be associated with considerable reduction in the quality of life compared to other dermatological conditions. ${ }^{8}$ Erythema nodosum leprosum (ENL) is associated with worse HRQoL in individuals in Bangladesh and Brazil. ${ }^{9,10}$

ENL affects approximately $50 \%$ of individuals with lepromatous leprosy (LL) and 5-10\% of borderline lepromatous (BL) leprosy patients. ${ }^{11}$ ENL is characterized by multiple tender, crops of erythematous cutaneous nodules, with inflammation of nerves and other organs. Neuritis during ENL episodes results in nerve function impairment. ENL is often chronic and may lead to impaired organ function. ${ }^{11}$ ENL is often treated with prolonged courses of high-dose oral corticosteroids which are associated with severe adverse effects and death. ${ }^{12}$ ENL is associated with more hospital visits and hospital admissions than other leprosy patients. ${ }^{13}$

ENL characteristically affects patients in their thirties ${ }^{12}$ which has consequences on the wider community as productivity is hampered and the family suffers. A previous study conducted in Purulia by us showed that families with ENL are affected by both out of pocket expenditure of treatment-seeking and loss of income household members. ${ }^{13}$ ENL therefore exacerbates the financial situation of individuals who are already economically insecure. ENL affects HRQoL in physical and psychological health domains. ${ }^{14}$

We aimed to measure HRQoL associated with ENL and compare it to individuals without ENL.

\section{Methods}

A cross-sectional study was conducted of individuals attending the Purulia Leprosy Mission Home and Hospital outpatient department between January and March 2015. The hospital is located in district of Purulia in the state of West Bengal in Eastern India. Purulia district is endemic for leprosy. ${ }^{15}$

Patients with leprosy including individuals newly diagnosed, those on MDT or those who had completed MDT were eligible to participate. Participants were classified as having ENL, Type 1 reaction (T1R), neuritis only and "no reaction or neuritis".

Ethical approval was obtained from the ethics committee of The Leprosy Mission (TLM) Trust India. Written informed consent was provided by all adult participants or the guardian for those under the age of 18 years.

\section{CASE DEFINITIONS}

Leprosy was diagnosed in individuals who had hypopigmented, anaesthetic skin patches and/or thickened nerves and/or acid-fast bacilli on slit skin smears. 
ENL was diagnosed if participants with BL leprosy or LL had crops of tender cutaneous or subcutaneous lesions.

Type1Reaction (T1R) was defined as the development of erythema and oedema of preexisting leprosy skin lesions. There may be accompanying neuritis and oedema of the hands, feet and face.

Neuritis was diagnosed if there was spontaneous nerve pain or tenderness; paraesthesia; new sensory or motor nerve impairment.

The Bengali version of the SF-36 was administered to assess HRQoL. ${ }^{16}$ A lower score reflects a worse HRQoL compared to a higher one. The SF-36 consists of 36 items and it generates subscale scores for Physical Functioning (PH), Role Limitations due to Physical problems (RP), Bodily Pain (BP), General Health perceptions (GH), Vitality (VT), Social Functioning (SF), Role-limitations due to Emotional Problems (RE), and Emotional WellBeing (MH). Two summary scores can also be derived from the SF-36: the Physical Component Summary (Physical Health) and the Mental Component Summary (Mental Health) which leads to an Overall Quality Score (HRQoL score).

The eight domains of SF-36 may be combined to derive physical health component (PHC) and mental health component (MHC) scores. The PHC includes domains of physical functioning (PF), role - physical (RP), bodily pain (BP) and general health $(\mathrm{GH})$. The MHC includes domains of vitality (VT), social functioning (SF), role-emotional (RE) and mental health $(\mathrm{MH})$.

Clinical and demographic data were collected using a standard form. A trained investigator recruited participants and conducted the interview in a private setting. Literate patients who were willing completed the questionnaire themselves.

Raw scale scores were summated and linearly transformed into a 0-100 scale assigned for each sub-domain, domain and overall HRQoL. A score ranging from 0 (indicating the worse health status) to 100 (indicating the best health status) and the higher scores indicating better health.

The data were entered in to Microsoft Excel database and analyzed using SPSS statistics programme. Simple frequencies and distribution measures were calculated for demographic and disease profile and compared using Chi-square test. The differences between groups were analyzed with independent ' $\mathrm{t}$ ' test. The threshold for accepting statistical significance was $p$ $<0.05$.

\section{Results}

Two hundred and ninety individuals with a median age of 32 years (Range 14-82) were recruited. Among the 290 participants, 44 (15.2\%) had ENL, 39 (13.4\%) T1R, 94 (32.4\%) neuritis and $113(39.0 \%)$ had no reaction/neuritis. One hundred and sixty-six $(57.2 \%)$ participants were literate, of this 94 (32.4\% in total patient) of them the questionnaire was selfadministered. Of the 290 participants, 184 were male and 106 (36.6\%) were female (Table 1).

The median time since leprosy diagnosis for the ENL group was 10 months. Among ENL patients, $9(23.1 \%)$ had completed MDT, $14(31.8 \%)$ patents with T1R and $39(41.5 \%)$ patients with neuritis had completed MDT. The disease profile was showed in Table 2.

\section{RELIABILITY ANALYSIS}

Internal consistency was assessed using Cronbach's alpha coefficients and corrected item-scale correlations. Corrected correlations between the items and their hypothesized scales ranged 
Table 1. Demographic profile of study participant $(n=290)$

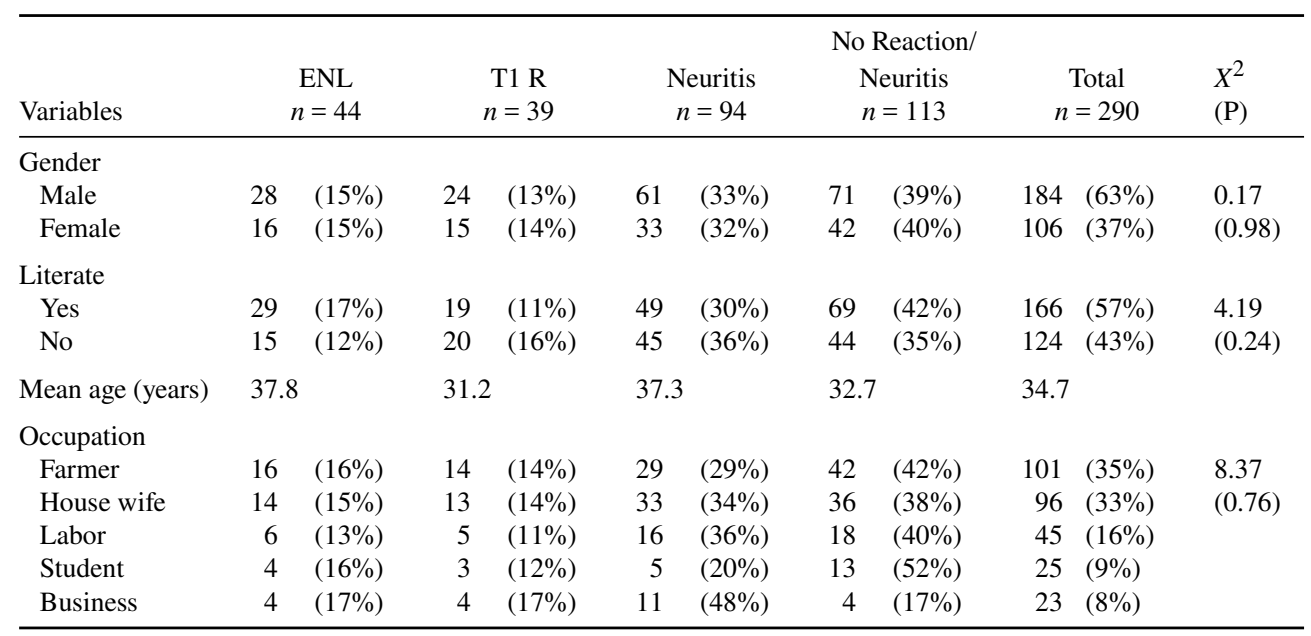

Note. Parenthesis indicates row percentages.

Table 2. Disease profile of study participant $(n=290)$

\begin{tabular}{|c|c|c|c|c|c|c|c|c|c|c|c|}
\hline \multirow{2}{*}{$\frac{\text { Variables }}{\text { Median tir }}$} & \multicolumn{2}{|c|}{$\begin{array}{c}\text { ENL } \\
n=44\end{array}$} & \multicolumn{2}{|c|}{$\begin{array}{c}\mathrm{T} 1 \mathrm{R} \\
n=39\end{array}$} & \multicolumn{2}{|c|}{$\begin{array}{c}\text { Neuritis } \\
n=94\end{array}$} & \multicolumn{2}{|c|}{$\begin{array}{c}\text { No R/Neuritis } \\
n=113\end{array}$} & \multicolumn{2}{|c|}{$\begin{array}{c}\text { Total } \\
n=290\end{array}$} & \multirow[t]{2}{*}{$\begin{array}{l}X^{2} \\
(\mathrm{P})\end{array}$} \\
\hline & epro & y diagno & & & & & & & & & \\
\hline In months & \multicolumn{2}{|l|}{8} & \multicolumn{2}{|l|}{10} & \multicolumn{2}{|l|}{7.5} & \multicolumn{2}{|l|}{8} & \multicolumn{2}{|l|}{8} & \\
\hline \multicolumn{12}{|c|}{ RJ Classification } \\
\hline $\mathrm{TT}$ & 0 & $(0 \%)$ & 0 & $(0 \%)$ & 0 & $(0 \%)$ & 3 & $(3 \%)$ & 3 & $(1 \%)$ & \\
\hline BT & 0 & $(0 \%)$ & 26 & $(67 \%)$ & 80 & $(85 \%)$ & 85 & $(75 \%)$ & 191 & $(66 \%)$ & 134.29 \\
\hline $\mathrm{BB}$ & 0 & $(0 \%)$ & 1 & $(3 \%)$ & 0 & $(0 \%)$ & 0 & $(0 \%)$ & 1 & $(0 \%)$ & $(0.000)$ \\
\hline BL & 25 & $(57 \%)$ & 8 & $(21 \%)$ & 4 & $(4 \%)$ & 14 & $(12 \%)$ & 51 & $(18 \%)$ & \\
\hline LL & 19 & $(43 \%)$ & 4 & $(10 \%)$ & 7 & $(7 \%)$ & 11 & $(10 \%)$ & 41 & $(14 \%)$ & \\
\hline PNL & 0 & $(0 \%)$ & 0 & $(0 \%)$ & 3 & $(3 \%)$ & 0 & $(0 \%)$ & 3 & $(1 \%)$ & \\
\hline \multicolumn{12}{|l|}{ MDT Status } \\
\hline Naïve & 1 & $(2 \%)$ & 8 & $(21 \%)$ & 20 & $(21 \%)$ & 34 & $(30 \%)$ & 63 & $(22 \%)$ & 22.14 \\
\hline Current & 29 & $(66 \%)$ & 22 & $(56 \%)$ & 35 & $(37 \%)$ & 47 & $(42 \%)$ & 133 & $(46 \%)$ & $(0.001)$ \\
\hline Completed & 14 & $(32 \%)$ & 9 & $(23 \%)$ & 39 & $(41 \%)$ & 32 & $(28 \%)$ & 94 & $(32 \%)$ & \\
\hline \multicolumn{12}{|c|}{ WHO Disability grade } \\
\hline Grade 0 & 24 & $(55 \%)$ & 16 & $(41 \%)$ & 15 & $(16 \%)$ & 101 & $(89 \%)$ & 156 & $(54 \%)$ & 117.21 \\
\hline Grade 1 & 6 & $(14 \%)$ & 9 & $(23 \%)$ & 19 & $(20 \%)$ & 3 & $(3 \%)$ & 37 & $(13 \%)$ & $(0.000)$ \\
\hline Grade 2 & 14 & $(32 \%)$ & 14 & $(36 \%)$ & 60 & $(64 \%)$ & 9 & $(8 \%)$ & 97 & $(33 \%)$ & \\
\hline \multicolumn{12}{|l|}{ Relapse } \\
\hline Yes & 1 & $(2 \%)$ & 4 & $(10 \%)$ & 0 & $(0 \%)$ & 1 & $(1 \%)$ & 6 & $(2 \%)$ & 15.68 \\
\hline No & 43 & $(98 \%)$ & 35 & $(90 \%)$ & 94 & $(100 \%)$ & 112 & $(99 \%)$ & 284 & $(98 \%)$ & $(0.001)$ \\
\hline
\end{tabular}

from 0.36 to 0.76 and were 0.4 or above for all items except for two items from the GH scale. Cronbach's alpha ranged from 0.924 (SF) to 0.937 (GH and $\mathrm{MH}$ ) and exceeded the 0.70 standard for all scales.

Furthermore, in patients with leprosy reaction, ENL affected patients had lower mean scores in all domains of SF-36 than the patients with T1R. 
Table 3. One-way ANOVA test between Disability Grade and domains of SF-36

\begin{tabular}{lccccccccc}
\hline Disability & \multicolumn{9}{l}{ Mean Score } \\
\cline { 2 - 10 } Grade & $n$ & PF & RP & RE & VT & MH & SF & BP & GH \\
\hline Grade 0 & 156 & 80.9 & 74.5 & 75.2 & 78.9 & 81 & 82.9 & 72.8 & 55.7 \\
Grade 1 & 37 & 80.1 & 60.1 & 58.6 & 76.2 & 76.4 & 75.3 & 63.2 & 50.8 \\
Grade 2 & 97 & 65.2 & 41 & 39.5 & 71.1 & 73.7 & 62.5 & 52.8 & 49.1 \\
$p$-value & & $0.000^{* *}$ & $0.000^{* *}$ & $0.000^{* *}$ & $0.009^{*}$ & $0.007 *$ & $0.000^{* *}$ & $0.000^{* *}$ & $0.014 *$ \\
\hline
\end{tabular}

Table 4. Independent ' $t$ ' test between No Reaction/neuritis vs ENL, T1R and Neuritis

\begin{tabular}{|c|c|c|c|c|c|c|c|}
\hline \multirow[b]{3}{*}{ Domain } & \multicolumn{4}{|c|}{ Mean score \pm Standard deviation } & \multirow{2}{*}{\multicolumn{3}{|c|}{$\begin{array}{c}\mathrm{p} \text {-value } \\
\text { No reaction/neuritis vs }\end{array}$}} \\
\hline & \multirow{2}{*}{$\begin{array}{l}\text { ENL } \\
(n=44)\end{array}$} & \multirow{2}{*}{$\begin{array}{l}\text { T1R } \\
(n=39)\end{array}$} & \multirow{2}{*}{$\begin{array}{l}\text { Neuritis } \\
(n=94)\end{array}$} & \multirow{2}{*}{$\begin{array}{l}\text { No reaction/ } \\
\text { neuritis } \\
(n=113)\end{array}$} & & & \\
\hline & & & & & $\overline{\mathrm{ENL}}$ & T1R & Neuritis \\
\hline $\mathrm{PF}$ & $73.07 \pm 23.482$ & $76.41 \pm 27.790$ & $71.60 \pm 23.557$ & $79.47 \pm 25.906$ & 0.156 & 0.534 & 0.024 \\
\hline $\mathrm{RP}$ & $52.84 \pm 47.070$ & $66.03 \pm 47.464$ & $47.07 \pm 47.215$ & $76.70 \pm 41.280$ & 0.001 & 0.246 & $<0.001$ \\
\hline RE & $50.76 \pm 49.015$ & $67.52 \pm 45.555$ & $44.68 \pm 48.281$ & $75.22 \pm 41.792$ & 0.004 & 0.255 & $<0.001$ \\
\hline VT & $70.45 \pm 20.398$ & $73.59 \pm 21.550$ & $73.94 \pm 19.301$ & $80.62 \pm 18.116$ & 0.003 & 0.049 & 0.011 \\
\hline MH & $71.27 \pm 19.525$ & $78.67 \pm 16.061$ & $75.91 \pm 19.250$ & $82.09 \pm 16.588$ & 0.001 & 0.265 & 0.014 \\
\hline SF & $67.57 \pm 35.857$ & $74.79 \pm 35.044$ & $68.13 \pm 36.196$ & $83.99 \pm 29.613$ & 0.004 & 0.113 & 0.001 \\
\hline BP & $59.77 \pm 35.372$ & $69.74 \pm 36.457$ & $55.38 \pm 38.082$ & $73.14 \pm 32.708$ & 0.026 & 0.588 & $<0.001$ \\
\hline $\mathrm{GH}$ & $49.66 \pm 15.863$ & $55.15 \pm 19.129$ & $48.26 \pm 18.269$ & $57.09 \pm 17.249$ & 0.014 & 0.558 & $<0.001$ \\
\hline $\mathrm{PHC}$ & $58.8 \pm 25.7$ & $66.8 \pm 27.8$ & $55.6 \pm 26.0$ & $71.2 \pm 23.5$ & 0.031 & 0.784 & 0.000 \\
\hline $\mathrm{MHC}$ & $65.0 \pm 27.4$ & $73.6 \pm 25.4$ & $65.7 \pm 25.1$ & $80.8 \pm 21.8$ & 0.002 & 0.381 & 0.000 \\
\hline
\end{tabular}

COMPARISON OF PARTICIPANT GENDER, OCCUPATION, RJ CLASSIFICATION AND DISABILITY GRADE WITH DOMAINS OF SF-36

There was no significant difference between gender, occupation and RJ classification in all the domains of SF-36. For Disability Grade, there was a significant difference observed in all the domains of SF-36 (Table 3).

COMPARISON OF PARTICIPANTS WITH ENL OR T1R OR NEURITIS AND PARTICIPANTS WITH NO REACTION OR NEURITIS

The "no reaction or neuritis" group had higher scores in all domains of SF-36 than the ENL group. There is a significant difference between the two groups in all domains except in PF (Table 4).

The "no reaction or neuritis" group had higher scores in all domains of SF-36 than the neuritis group. The differences were statistical significant in all domains (Table 4).

The "no reaction or neuritis" group had higher scores in all domains of SF-36 than T1R group. However, there is a significant difference seen only in VT domain (Table 4).

\section{PHYSICAL COMPONENT AND MENTAL COMPONENT}

Individuals with ENL had significantly worse HRQoL than patients with "no reaction or neuritis" in both the PHC and MHC. This was also the case for individuals with neuritis who had significantly worse HRQoL compared with those without reaction or neuritis. There was no significant difference found in HRQoL between individuals with T1R and those without reaction or neuritis in both the PHC (Figure 1) and MHC (Figure 2). 


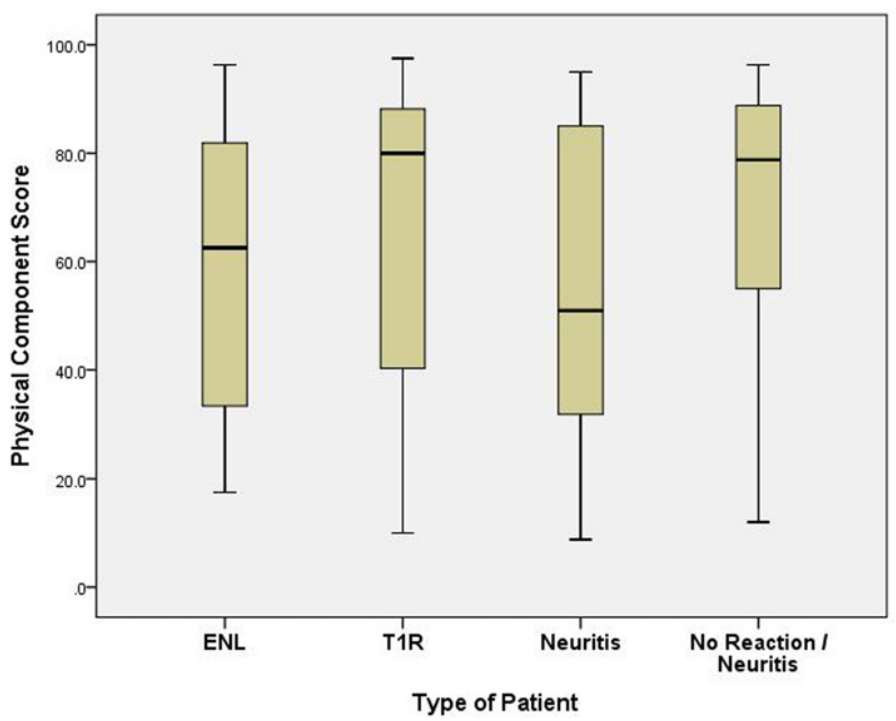

Figure 1. Physical Component Score for the study participants.

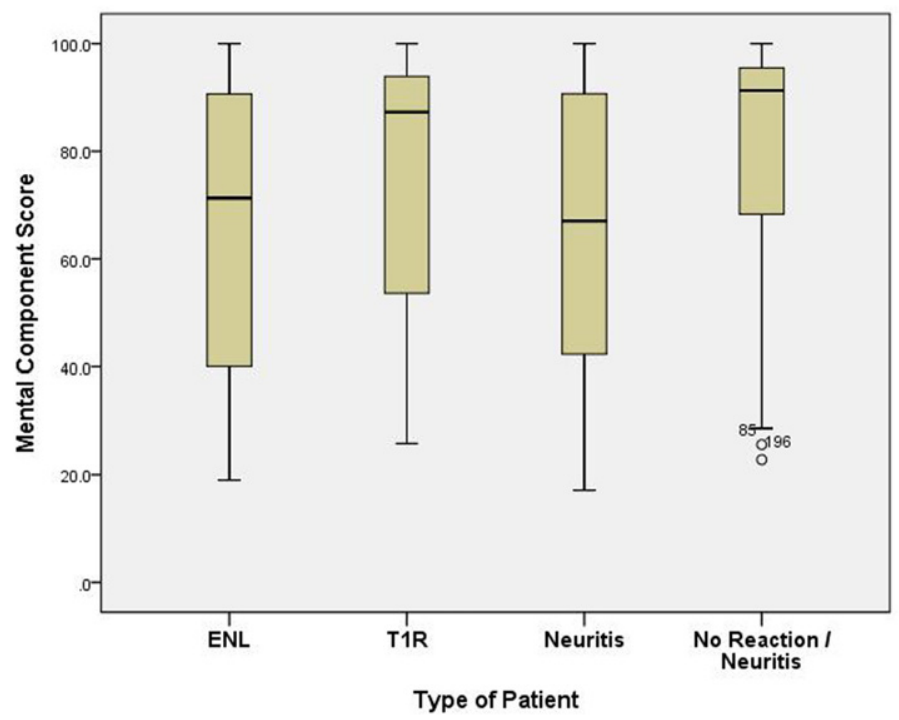

Figure 2. Mental Component Score for the study participants.

\section{Discussion}

This is the first study from India to examine HRQoL of individuals with ENL, T1R and those with isolated neuritis. Studies from India, using the WHOQOL-bref questionnaire found that leprosy affected people had lower QoL scores than the non-leprosy affected general population especially in the physical and psychological domains. ${ }^{17}$ 
Studies from Bangladesh and Brazil reported that ENL is associated with a severe impact on HRQoL. ${ }^{9,10}$ In this study, a significant difference was found between individuals with ENL or those with isolated neuritis and participants without reaction or neuritis. ENL affected patients had lower HRQoL in all domains except in physical functioning than patients without reaction or neuritis. In Bangladesh, Bowers et al. ${ }^{9}$ using the Bengali version of the SF-36 found that patients with ENL had lower HRQoL in the domains than individuals without ENL. ${ }^{9}$ A similar study by Sales et al. ${ }^{10}$ in Brazil found that people with ENL had impaired HRQoL compared to those without ENL, however the difference was only significant in the bodily pain domain. ${ }^{10}$

Studies from Brazil using the WHOQOL-bref questionnaire showed that participants with "leprosy reactions" tend to have more severe impairment in the physical domain. ${ }^{18}$ Lustosa et al. measured HRQoL by SF-36, found that individuals with leprosy reactions in Brazil had significantly lower HRQoL than those with no reaction. ${ }^{19}$ Participants with T1R had a significant lower HRQoL score than those without reaction or neuritis, however this only statistically significant in the VT domain. The impact of neuritis on HRQoL may be due to NFI, neuropathic pain and disability and the contribution of such factors need to be further clarified. ${ }^{20}$ In this study, patient with neuritis had a significant lower HRQoL score in all domains than the patients without reaction/neuritis.

Our study has limitations. The study was cross-sectional and did not have matched controls. The SF-36 is a general tool and may not reflect specific aspects of ENL and leprosy which may have an important bearing on HRQoL.

In conclusion, this is the first study from India to show that ENL and neuritis is associated with reduced HRQoL. Further prospective, adequately powered longitudinal studies should be conducted which control for potential confounders including reactions with concomitant neuritis. We suggest that HRQoL should be measured try and better understand the impact of the disease on well-being, especially for patients with ENL and neuritis.

\section{Acknowledgements}

We would like to express our sincere thank all to all the individuals who participated in this study, Dr. Famkima Darlong, Head-Healthcare, The Leprosy Mission Trust India, New Delhi (Formerly, Superintendent, The Leprosy Mission Hospital, Purulia, West Bengal, India) for his guidance and encouragement, and The Leprosy Mission Trust India, Research Domain for their support.

\section{Author's Contribution}

Joydeepa Darlong, was involved in study conceptualization and design, implementation of the study, monitoring the study and manuscript writing.

Pitchaimani Govindharaj, was involved in monitoring the study, conducted the interview, data analysis, and manuscript writing.

Babananda Mahato, involved in identifying the study participants and conducted the interview.

Diana N. Lockwood, was involved in study conceptualization and design and co-ordinated the study.

Stephen L Walker, was involved in study conceptualization, design, data analysis, coordinated the study and commented on the manuscript. 


\section{References}

1 Scollard DM, Adams LB, Gillis TP, Krahenbuhl JL, Truman RW, Williams DL. The continuing challenges of leprosy. Clin Microbiol Rev, 2006; 19(2): 338-381.

2 World Health Organization. Global leprosy update, 2016: accelerating reduction of disease burden. Wkly Epidemiol Rec, 2017; 92(35): 501-520.

3 National Leprosy Eradication Programme (NLEP). Annual Report for the year 2015-16. Accessed on 06 July. 2017. Available at: http://nlep.nic.in/pdf/revised\%20annual\%20report\%2031st\%20March\%202015-16.pdf.

4 Sales AM, Campos DP, Hacker MA, da Costa Nery JA, Düppre NC, Rangel E, Sarno EN, Penna ML. Progression of leprosy disability after discharge: is multidrug therapy enough?. Trop Med Int Health, 2013; 18(9): 11451153 .

5 Brouwers C, van Brakel W, Cornielje H. Quality of life, perceived stigma, activity and participation of people with leprosy-related disabilities in south-east Nepal. Disability, CBR \& Inclusive Development, 2011; 22(1): 16-34.

6 The WHOQOL Group . What quality of life?. In: World Health Forum. vol. vol. 17, Geneva: World Health Organization 1996; pp. 354-356.

7 Tejada CD, Mendoza-Sassi RA, Almeida Jr HL, Figueiredo PN, Tejada VF. Impact on the quality of life of dermatological patients in southern Brazil. An Bras Dermatol, 2011; 86(6): 1113-1121.

8 An JG, Ma JH, Xiao SX, Xiao SB, Yang F. Quality of life in patients with lepromatous leprosy in China. J Eur Acad Dermatol Venereol, 2010; 24(7): 827-832.

9 Bowers B, Butlin CR, Alam KH, Lockwood DN, Walker SL. Health-Related Quality of Life amongst people affected by Erythema Nodosum Leprosum in Bangladesh: a Cross Sectional Study. Lep Rev, 2017; 88(4): 488498.

10 Sales AM, Illarramendi X, Walker SL, Lockwood D, Sarno EN, Da Costa Nery JA. The impact of Erythema Nodosum Leprosum on health related quality of life in Rio de Janeiro. Lep Rev, 2017; 88(4): 499-509.

11 Pocaterra L, Jain S, Reddy R, Muzaffarullah S, Torres O, Suneetha S, Lockwood DN. Clinical course of erythema nodosum leprosum: an 11-year cohort study in Hyderabad, India. Am J Tropical Medicine Hygiene, 2006; 74(5): 868-879.

12 Walker SL, Balagon M, Darlong J, Doni SN, Hagge DA, Halwai V, John A, Lambert SM, Maghanoy A, Nery JA, Neupane KD. ENLIST 1: an international multi-centre cross-sectional study of the clinical features of erythema nodosum leprosum. PLoS Negl Trop Dis, 2015; 9(9): e0004065.

13 Walker SL, Lebas E, Doni SN, Lockwood DN, Lambert SM. The mortality associated with erythema nodosum leprosum in Ethiopia: a retrospective hospital-based study. PLoS Negl Trop Dis, 2014; 8(3): e2690.

14 Schreuder PA, Naafs B. Chronic recurrent ENL, steroid dependent: long-term treatment with high dose clofazimine. Lepr Rev, 2003; 74(4): 386-389.

15 National Leprosy Eradication Programme (NLEP). District Wise PR \& NCDR as on March 2015. (Retrieved on July 06, 2017 from http://nlep.nic.in/pdf/Disttwise\%20NCDR-Mar.15\%20.pdf).

16 Feroz AH, Islam MN, ten Klooster PM, Hasan M, Rasker JJ, Haq SA. The Bengali Short Form-36 was acceptable, reliable, and valid in patients with rheumatoid arthritis. J Clin Epidemiol, 2012; 65(11): 1227-1235.

17 Joseph GA, Rao PS. Impact of leprosy on the quality of life. Bull World Health Organization, 1999; 77(6): 515.

18 Costa MD, Terra FD, Costa RD, Lyon S, Costa AM, Antunes CM. Assessment of quality of life of patients with leprosy reactional states treated in a dermatology reference center. An Bras Dermatol, 2012; 87(1): $26-35$.

19 Lustosa AA, Nogueira LT, Pedrosa JIDS, Teles JBM, Campelo V. The impact of leprosy on health-related quality of life. Rev Soc Bras Med Trop, 2011; 44(5): 621-626.

20 Lasry-Levy E, Hietaharju A, Pai V, Ganapati R, Rice ASC, Haanpää M et al. Neuropathic pain and psychological morbidity in patients with treated leprosy: A cross-sectional prevalence study in Mumbai. PLoS Negl Trop Dis, 2011; 5(3): e981, doi:10.1371/journal.pntd.0000981. 